\title{
Constraint counting on RNA and ribosomal structures: linking flexibility and function
}

\author{
Simone Fulle*, Holger Gohlke \\ From 6th German Conference on Chemoinformatics, GCC 2010 \\ Goslar, Germany. 7-9 November 2010
}

The ribosome is a large ribonucleoprotein complex that carries out protein synthesis in all kingdoms of life by translating genetic information encoded in mRNA into the amino acid sequence of a protein. The nascent polypeptides escape the peptidyl transferase center through the ribosomal exit tunnel that spans the entire large subunit. The tunnel is involved in the control of cotranslational protein folding processes, the regulation of elongation and the inhibition of the protein synthesis by antibiotics [1]. Since the structure determination of the ribosome in atomic detail in 2000, much has been learned about the structural basis for protein synthesis. However, the functional role of the ribosomal exit tunnel has remained elusive and has been controversially discussed.

We thus set out to analyze global and local flexibility characteristics of the ribosomal exit tunnel by constraint counting on topological network representations of large ribosomal subunits from four different organisms $[2,3]$. The analyses provide critical insights into the role of the ribosomal exit tunnel during protein synthesis. The flexibility characteristics of the tunnel will be used to answer questions such as: What is the origin of speciesselectivity of antibiotics binding? How is the co-translational elongation regulation regulated? What is the mechanism for signal transmission through the ribosomal structure?

\section{Published: 19 April 2011}

\section{References}

1. Kramer G, Boehringer D, Ban N, Bukau B: The ribosome as a platform for co-translational processing, folding and targeting of newly synthesized proteins. Nat. Struct. Mol. Biol. 2009, 16:589-597.

* Correspondence: fulle@uni-duesseldorf.de

Institute of Pharmaceutical and Medicinal Chemistry, HHU, Düsseldorf, Germany
2. Fulle $\mathrm{S}$, Gohlke $\mathrm{H}$ : Analysing the flexibility of RNA structures by constraint counting. Biophys. J. 2008, 94:4202-4219.

3. Fulle S, Gohlke H: Statics of the ribosomal exit tunnel: Implications for co-translational peptide folding, elongation regulation, and antibiotics binding. J. Mol. Biol. 2009, 387:502-517.

doi:10.1186/1758-2946-3-S1-011

Cite this article as: Fulle and Gohlke: Constraint counting on RNA and ribosomal structures: linking flexibility and function. Journal of Cheminformatics 2011 3(Suppl 1):011.

\section{Publish with ChemistryCentral and every scientist can read your work free of charge \\ "Open access provides opportunities to our colleagues in other parts of the globe, by allowing anyone to view the content free of charge." \\ W. Jeffery Hurst, The Hershey Company. \\ - available free of charge to the entire scientific community \\ - peer reviewed and published immediately upon acceptance \\ - cited in PubMed and archived on PubMed Central \\ - yours - you keep the copyright \\ Submit your manuscript here: \\ http://www.chemistrycentral.com/manuscript/}

